\title{
Chronic pulmonary heart disease
}

\author{
Arthur J. Thomas ${ }^{1}$
}

Chronic cor pulmonale has been defined as hypertrophy of the right ventricle resulting , from diseases affecting the function and/or structure of the lung except when these alterations are the result of diseases which primarily affect the left side of the heart or congenital heart diseases (World Health Organization, 1963). Right ventricular hypertrophy is defined as a pathological condition and may not be clinically detectable in its earliest stages when the pulmonary disease is already causing an increase in right ventricular work. Cor pulmonale is not synonymous with heart failure because the right ventricular hypertrophy can be present for long periods without the heart failing. Pulmonary heart disease may be a better description of - the overall condition of the right heart from the time it is first affected by pulmonary disease to the final failure.

The increased work load is due to pulmonary hypertension which may be vasoconstrictive or obstructive (obliterative) or a mixture of both. Vasoconstrictive pulmonary hypertension is the result of disorder of alveolar or blood gases and is reversible. Obstructive pul- monary hypertension in chronic bronchitis is thought to be due to longstanding vasoconstriction of the small pulmonary arteries complicated later by minor infective thickening of the pulmonary arterioles. In pneumoconiosis, bronchiectasis, sarcoidosis, and similar diseases local permanent small artery lesions moccur, to be later complicated by the effects of chronic bronchitis. Obstructive pulmonary - hypertension can follow thromboembolic disease. A list of diseases capable of causing - pulmonary heart disease is given in the World 1 Health Organization Report (1963). Right heart failure is a late stage and always associated with severe pulmonary hypertension and often severe hypoxia. Hypercapnia may be responsible for oedema due to renal retention of salt and water without right heart failure.

1 Address: University Hospital of Wales (Llandough Hospital, Penarth, Glamorgan).
Haemodynamic studies suggest three stages in the development of pulmonary heart disease (Kremer, 1969): (I) pulmonary arterial hypertension during exercise; (2) pulmonary arterial hypertension already present at rest; and (3) pulmonary arterial hypertension with right ventricular failure.

This does not involve cardiac catheterization in every patient; it is possible to correlate these steps with the clinical findings and the severity of the respiratory disorder. There will be exceptions in some forms of obstructive pulmonary hypertension when ventilatory tests give good results, for example in thromboembolism. Coincident diseases of the left heart, especially coronary artery disease, will further complicate the picture. The pulmonary circulation and cor pulmonale are the subject of much writing (Adams and Veith, I959; Platts, Hammond, and Stuart-Harris, 1960; Harris and Heath, 1962; Turino, Goldring, and Fishman, I965; Ferrer, I965; Cournand, 1966; Oakley and Goodwin, 1967; Lee, I97I).

The mean pulmonary arterial pressure $(\overline{\mathrm{P}} \mathrm{pa})$ in normal subjects at rest is below 20 $\mathrm{mmHg}$ but the exact reading depends on technique. Many workers consider that $\overline{\mathrm{P}} \mathrm{pa}$ between $15 \mathrm{mmHg}$ and $20 \mathrm{mmHg}$ may be normal or abnormal. Exercise in normal subjects causes an increase in $\overline{\mathrm{P}}$ pa depending on the age of the subject and the degree of effort, the increase being greater in subjects over 50 years. In the majority on submaximal exercise Ppa should not exceed $30 \mathrm{mmHg}$ though some workers have recorded pressures of 35 $\mathrm{mmHg}$ as normal (Donald et al., 1955; Denolin, 1961, 1966; Ekelund and Holmgren, 1967; Fowler, 1969; Kremer, 1969).

In severe chronic bronchitis and particularly in those with clinical right ventricular hypertrophy or failure $\overline{\mathbf{P}}$ pa is much raised at rest (Ferrer and Harvey, 1959). In moderately severe chronic bronchitis with a forced expiratory volume in one second $\left(\mathrm{FEV}_{1}\right)$ below $\mathrm{I} \cdot 2$ litres and reduced $\mathrm{FEV}_{1} / \mathrm{VC}$ percentage the 
$\mathrm{Ppa}$ is raised at rest. When the $\mathrm{FEV}_{1}$ lies between $\mathrm{I} \cdot 2$ litres and $2 \cdot 0$ litres and a reduced $\mathrm{FEV}_{1} / \mathrm{VC}$ percentage the $\overline{\mathrm{P}}$ pa may be normal at rest but always increases more than normal on exercise (Cotes, Pisa, and Thomas 1963; Horsfield, Segel, and Bishop, 1968; Kremer, 1969). There is a significant relation between $\overline{\mathrm{P}} \mathrm{pa}$ at rest and $\mathrm{FEV}_{1}$ in these patients $(\mathrm{r}=$ -0.55 ). When the $\bar{P}$ pa is persistently raised at rest right ventricular hypertrophy develops. When pulmonary fibrosis coexists with chronic bronchitis, as in many patients with pneumoconiosis, the $\bar{P}$ pa again closely correlates with the $\mathrm{FEV}_{1}$, at rest $(\mathrm{r}=-0.706)$, and during exercise $(r=-0.625)$. However, patients with progressive massive fibrosis of pneumoconiosis can develop obstructive pulmonary hypertension without gross reduction of ventilatory function though this is not usual. Haemodynamic studies in coalworkers with simple pneumoconiosis suggest that it is those with obstructive airways disease who develop pulmonary hypertension (Sadoul et al., 1968; Lapp et al., 1971). Field and Cotes (1970) studied coalworkers with early progressive massive fibrosis and showed that the pulmonary circulation was not impaired except when there was superimposed bronchitis. From a study of pressure/flow curves they suggest that a reduction in the ability of the pulmonary vascular bed to accommodate an increase in blood flow during exercise occurs early in the natural history of bronchitis. These workers also regard these findings as evidence of a vascular sluice with a reduction in critical closing pressure of the vessels at the site of the vascular waterfall. Lee (I97I) in his work on the pulmonary circulation and capillary flow has demonstrated that the diminished distensibility and decreased compliance of the pulmonary arterial system in the presence of increased pulmonary arterial resistance plays an important part in maintaining the flow characteristics of blood entering the capillary system. In the more severe pulmonary vascular disease this relation between pulmonary arterial resistance and compliance may break down.

In moderately severe chronic bronchitis with no heart failure the cardiac output at rest is normal and the response on exercise is within normal limits (Wade and Bishop, 1962; Horsfield et al., 1968; Field and Cotes, 1970). Severe chronic bronchitis with heart failure causes a fall in cardiac output to low normal or subnormal values. In the 1950's these cardiac outputs were found to be high normal or even high but in recent years the values have fallen. Ferrer (1965) has attributed this fall of cardiac output over 20 years to better management of the pulmonary disease, particularly of the infective element. The more accurate identification and exclusion of patients with bronchiolectasis whose cardiac output would be in the higher range would explain some of the change. Clearly, investigation and therapy of chronic pulmonary heart disease is producing important results.

In chronic bronchitis rise in the $\bar{P}$ pa correlates well with the fall in arterial oxygen tension $\left(\mathrm{PaO}_{2}\right)(\mathrm{r}=-0.609)$ and arterial oxygen saturation $\left(\mathrm{SaO}_{2}\right)$ at rest $(\mathrm{r}=-0.47)$ and during exercise $(\mathrm{r}=-0.68)$ (Cotes et al., 1963; Kremer, 1969). The relation of raised Ppa to hypoxia is emphasized by the effect of oxygen breathing in patients with chronic bronchitis. Cotes et al. (1963) demonstrated a fall of IO.I per cent in $\bar{P}$ pa from 43.8 $\mathrm{mmHg}$ to $39 \mathrm{mmHg}$. Field and Cotes (1970) found that the pressure/flow curves were displaced downward on oxygen breathing and more so in chronic bronchitis. Abraham, Cole, and Bishop (I968) show that after the immediate fall in $\overline{\mathbf{P}}$ pa on short-term oxygen administration the residual established pulmonary hypertension can be reduced by long-term oxygen administration ( 4 to 8 weeks). This reversal may be due to regression of the muscular hyperplasia of the small pulmonary vessels. The fall in $\bar{P}$ pa was not maintained after oxygen breathing was stopped. With increasing disability there is an increase in cardiac frequency, relative to the oxygen uptake, and either no change or a slight fall in stroke volume. The cardiac frequency is much reduced on breathing oxygen, both at rest and on exercise. The right side of the heart deals with the increased work load in a normal manner, but the increase above normal frequency is a good clinical measure of the increased cardiac work required.

Hypoxic pulmonary hypertension without infection leads to right ventricular hypertrophy in man at high altitude and in the experimental animal at reduced atmospheric pressures. In mice exposed to half atmospheric pressure for 19 days, severe right ventricular hypertrophy developed and some, but not all, showed thickening of arteriolar walls and duplication of the elastic lamina (James and Thomas, 1968). There was some individual variation in the susceptibility of the animals. Abraham et al. (197I) have shown that rats exposed to chronic hypoxia develop an increase in right ventricular mean pressure, right ventricular hypertrophy, and a characteristic form of hypertensive pulmonary vascular disease but, more important, when these animals are removed from the hypoxic environment there is a progressive 
reduction of the right ventricular pressure, a regression of the pulmonary vascular disease, and a return of left-to-right ventricular ratio towards control values. If these findings are applicable to human subjects, and the work of Grover et al. (1966) on high altitude pulmonary hypertension suggests that they are, prevention of hypoxia in subjects with pulmonary disease is all important. Hypoventilation is a major cause of hypoxia in many patients with chronic obstructive airways disease and with the hypoventilation syndrome. In these patients there is a decline of hypoxic ventilatory drive which is progressive and maintains the hypoxia leading to increasing vascular change due to pulmonary hypertension. This applies in the type B chronic bronchitis and in the many forms of hypoventilation syndrome, including the musculoskeletal diseases of the thorax, and obesity. Ventilation perfusion inequality, a large subject in itself, plays a major role in the hypoxia and increased vascular resistance of chronic obstructive airways disease of all forms (West, 1965).

Wide consideration has been given to the site of the stimulus for pulmonary vasoconstrictive hypertension. Bergofsky and Haas (1967) have shown experimentally that decrease in oxygen tension affecting the precapillary segment causes an increase in Ppa, and further proved that alveolar hypoxia caused the greatest rise in pulmonary vascular resistance $(50 \%)$, and the pressor response of alveolar hypoxia was noticeably less if the pulmonary arterial blood was well oxygenated. They and other workers suggest that the small pulmonary arteries are sensitive to alveolar hypoxia and to increased or decreased hydrogen ion concentration. A suggested mechanism for this effect is the interference with sodium and potassium exchanges across the smooth muscle cell membrane favouring depolarization and increasing action potentials (Bergofsky and Holtzman, 1967). Potassium depletion in patients with chronic respiratory failure has been shown by Mills (1968) and Schloerb et al. (1970), and they have shown that the degree of depletion of body potassium is not adequately reflected in the serum potassium level. It is very likely that many of the cardiac arrhythmias associated with pulmonary heart disease arise from this same potassium depletion of myocardial cells and similarly the sensitivity of pulmonary heart disease to digitalis may be explained (Thomas and Valabhji, 1969).

The effect of change of hydrogen ion concentration is still debated. Enson et al. (1964) showed an increasing $\bar{P}$ pa response to hypoxia with increasing hydrogen ion concentration and Gomez developed an equation correlating hypoxia and hydrogen ion with pulmonary artery pressures, a graph of which is of clinical value. Housley et al. (1970) were unable to confirm this effect of acidaemia and hypoxia in chronic bronchitis. Experimentally reducing blood $\mathrm{pH}$ in control and hypoxic animals produces rises in $\overline{\mathrm{P}} \mathrm{pa}$ and increases in pulmonary vascular resistance (Barer, McCurrie, and Shaw, 1971). Our experience confirms these findings.

There are many other factors in the pulmonary hypertension and right ventricular hypertrophy of chronic bronchitis. Airways resistance and increased alveolar pressure can influence the pulmonary vascular resistance and may be important in the local changes in resistance (Harris et al., 1968). The level of total and central blood volume contributes to the pulmonary hypertension in chronic bronchitis, but blood viscosity has little effect (Segel and Bishop, I966). Hypercapnia is a debatable factor in the production of pulmonary hypertension; there is always a correlation $(r=0.5)$ but this is not of necessity causative. Clearly hypercapnia has an effect on salt and water retention and so can indirectly affect pulmonary arterial pressure and also produce oedema and mimic heart failure (White and Woodings, 1971).

Emphysema alone shows little correlation with the weight of the right ventricle. Severe emphysema reaching 80 per cent can be present with a normal right ventricle, but 45 per cent of emphysema with chronic bronchitis gives right ventricular hypertrophy (Dunnill, I96I ; Bignon, 1967). Asthma alone does not correlate with right ventricular hypertrophy.

There remains the problem of the left ventricular state. Many workers have found unexplained left ventricular hypertrophy in pulmonary heart disease. Coincident ischaemic heart disease is common in chronic bronchitis and pneumoconiosis but no commoner, and possibly less common, than in the population generally (Bhargava and Woolf, I97I ; Mitchell, Walker, and Maisel, 1968). Saunders (1970) found that a majority of patients with simple pneumoconiosis died of coronary artery disease but only a minority of those with progressive massive fibrosis. Could it be that progressive massive fibrosis protects the patients from the more severe effects of coronary heart disease ? A study of left ventricular function in chronic obstructive pulmonary disease has shown a normal response to an increased pressure load and no evidence of impairment of left ventricular function (Williams et al., 1968).

In many studies raised pulmonary arterial 
wedge pressures have been found in some patients with chronic bronchitis alone or with pneumoconiosis and there is further increase on exercise. This increase of wedge pressure could be due to a combined effect of large intrathoracic pressure swing and an increase in the haemodynamic load of the left ventricle (Lockhart et al., 1969, 1970). Jesek and Herles (1969) say that different readings of wedge pressure can be obtained from different parts of the lungs in obstructive airways disease due to local changes. This finding may explain some of the discrepancies but not all and a raised wedge pressure must be accepted in some cases. Whatever the explanation of the occasional left ventricular hypertrophy, it is oftener seen in chronic bronchitis than in progressive massive fibrosis of pneumoconiosis. Moret, Bopp, and Panos (1967) have shown that the coronary circulation of chronic pulmonary disease with hypoxaemia is not comparable to that of the normal subject with acute hypoxaemia. In the former the coronary flow does not increase and is often diminished and there is evidence of anaerobic metabolism. If this is associated with some degree of coronary atherosclerosis the two together may well affect the myocardium of the left ventricle.

The electrocardiogram should prove of value in detecting pulmonary heart disease and in excluding ischaemic heart disease but has been found to be only 70 per cent effective (Rees, Thomas, and Rossiter, 1964). Many electrocardiographic criteria of right ventricular hypertrophy in pulmonary disease have been proposed and these have recently been reviewed by Kremer (1969). He suggests two or more of the following: (I) $P \geqslant 3 \mathrm{~mm}$ in standard leads; (2) $\bar{A} Q R S \geqslant+110^{\circ}$ or $\bar{A} Q R S$ $+100^{\circ}$ with negative $T$ in lead III or a Lewis index $\geqslant 15 \mathrm{~mm}$; (3) $R / S>I$ in $V I, R / S \leqslant I$ in V6 or $R<5 \mathrm{~mm}$ in V6; (4) negative $T$ wave $\mathrm{VI}$ to $\mathrm{V} 3$.

In the presence of pulmonary arterial hypertension at rest two or more of these were present in 56.6 per cent of his cases.

It is doubtful that the electrocardiogram or vectorcardiogram can identify the early changes of right ventricular hypertrophy when they are confined to the crista supraventricularis and adjacent outflow tract, but they are more likely to succeed when pressure overload causes further hypertrophy (Hunsaker et al., I970).

The clinical aspects of pulmonary heart disease have been described by Oakley and Goodwin (1967). Recent work should be applied to improve the clinical assessment of these patients by combining measurement of blood gases at rest and on exercise, detailed analyses of lung function, the effect of oxygen breathing at rest and on exercise on cardiac frequency, electrocardiographic analysis, and a full clinical assessment. The aim of assessment is to enable treatment to halt or reverse the disease process before permanent pulmonary vascular changes can develop. That this can be done is recognized by workers in this field and the changes in the pattern of pulmonary heart disease and right heart failure over the years are evidence of some success.

\section{References}

Abraham, A. S., Cole, R. B., and Bishop, J. M. (1968). Reversal of pulmonary hypertension by prolonged oxygen administration to patients with chronic bronchitis. Circulation Research, 23, I47.

Abraham, A. S., Kay, J. M., Cole, R. B., and Pincock, A. C. (I97I). Haemodynamic and pathological study of the effect of chronic hypoxia and subsequent recovery of the heart and pulmonary vasculature of the rat. Cardiovascular Research, 5, 95.

Adams, W. R., and Veith, I. (1959). (Eds.) Pulmonary Circulation. Grune and Stratton, New York.

Barer, G. R., McCurrie, J. R., and Shaw, J. W. (197I). Effect of changes in blood $\mathrm{pH}$ on the vascular resistance of the normal and hypoxic cat lung. Cardiovascular Research, 5, 490.

Bergofsky, S. H., and Haas, F. (1967). In Entretiens de Physio-Pathologie Respiratoire, $7^{\ominus}$ Serie. GauthierVillars, Paris.

Bergofsky, E. H., and Holtzman, S. (1967). A study of the mechanisms involved in the pulmonary arterial pressor response to hypoxia. Circulation Research, 20, 506.

Bhargava, R. K., and Woolf, C. R. (I97I). Relationship between ischaemic heart disease and chronic diffuse pulmonary disease. Chest, 59, 254.

Bignon, J. (1967). In Entretiens de Physio-Pathologie Respiratoire, $7^{\ominus}$ Serie. Gauthier-Villars, Paris.

Cotes, J. E., Pisa, Z., and Thomas, A. J. (1963). Effect of breathing oxygen upon cardiac output, heart rate, ventilation, systemic and pulmonary blood pressure in patients with chronic lung disease. Clinical Science, 25, 305.

Cournand, A. (1966). The pulmonary circulation in normal man and in chronic cardio-pulmonary diseases. In 5th World Congress of Cardiology Symposia, p. 5. Acta Cardiologica, Brussels.

Denolin, H. (I96I). Contribution à l'étude de la circulation pulmonaire en clinique. Acta Cardiologica, I6, Suppl. $\mathrm{X}$.

Denolin, H. (1966). La circulation pulmonaire dans les pneumopathies chronique. Poumon et le Couer, 22, 793.

Donald, K. W., Bishop, J. M., Cumming, G., and Wade, O. L. (1955). The effect of exercise on the cardiac output and circulatory dynamics of normal subjects. Clinical Science, 14, 37.

Dunnill, M. S. (196I). An assessment of the anatomical factor in cor pulmonale in emphysema. Fournal of Clinical Pathology, 14, 246.

Ekelund, L. G., and Holmgren, A. (1967). Central haemodynamics during exercise. Circulation Research, 20, Suppl. I, 33. 
Enson, Y., Giuntini, C., Lewis, M. I., Morris, T. Q., Ferrer, M. I., and Harvey, R. M. (1964). The influence of hydrogen ion concentration and hypoxia on the pulmonary circulation. Fournal of Clinical Investigation, 43, II46.

Ferrer, M. I. (1965). Disturbances in the circulation in patients with cor pulmonale. Bulletin of the New York Academy of Medicine, 41, 942.

Ferrer, M. I., and Harvey, R. M. (1959). Decompensated pulmonary heart disease. In Pulmonary Circulation, p. I7I. Ed. by W. Adams and I. Veith. Grune and Stratton, New York.

Field, G. B., and Cotes, J. E. (1970). Lability of pulmonary pressure/flow curves during exercise in clinically mild bronchitis; evidence for a pulmonary vascular sluice in man. Clinical Science, 38, 46I.

Fowler, N. O. (1969). The normal pulmonary arterial pressure-flow relationships during exercise. American fournal of Medicine, 47, $\mathrm{r}$.

Grover, R. F., Vogel, J. H. K., Voigt, G. C., and Blount, S. G. (1966). Reversal of high altitude pulmonary hypertension. American fournal of Cardiology, 18, 928.

Harris, P., and Heath, D. (1962). The Human Pulmonary Circulation. Livingstone, Edinburgh.

Harris, P., Segel, N., Green, I., and Housley, E. (I968). The influence of the airways resistance and alveolar pressure on the pulmonary vascular resistance in chronic bronchitis. Cardiovascular Research, 2, 84

Horsfield, K., Segel, N., and Bishop, J. M. (1968). The pulmonary circulation in chronic bronchitis at rest and during exercise breathing air and $80 \%$ oxygen. Clinical Science, 34, 473.

Housley, E., Clarke, S. W., Hedworth-Whitty, R. B., and Bishop, J. M. (1970). Effect of acute and chronic acidaemia and associated hypoxia on the pulmonary circulation of patients with chronic bronchitis. Cardiovascular Research, 4, 482.

Hunsaker, M. R., Kaplan, K., Donnelly, J., and Lapp, N. L. (1970). The Frank vectorcardiogram in coal miners' pneumoconiosis. Fournal of Electrocardi$o \log y, 3,155$.

James, W. R. L., and Thomas, A. J. (I968). The effect of hypoxia on the heart and pulmonary arterioles of mice. Cardiovascular Research, 2, 278.

Jesek, V., and Herles, F. (1969). Uneven distribution of pulmonary arterial wedge pressure in chronic bronchitis and emphysema. Cardiologia, 54, I64.

Kremer, R. (1969). Apport de l'Hémodynamique Pulmonaire de l'Étude de la Pneumoconiose des Houilleurs. L. and A. Maris, Hasselt.

Lapp, L. N., Seaton, A., Kaplan, K. C., Hunsaker, M. R., and Morgan, W. K. C. (I97I). Pulmonary haemodynamics in symptomatic coal-miners. American Review of Respiratory Diseases, 104, 418.

Lee, G. de J. (1971). Regulation of the pulmonary circulation. British Heart fournal, 33, Suppl., I5.

Lockhart, A., Nader, F., Tzareva, M., and Schrijen, F. (1970). Comparative effects of exercise and isocapnic voluntary hyperventilation on pulmonary haemodynamics in chronic bronchitis and emphysema. European fournal of Clinical Investigation, $\mathbf{r}$, 69.

Lockhart, A., Tzareva, M., Nader, F., Leblanc, P., Schrijen, F., and Sadoul, P. (I969). Elevated pulmonary artery wedge pressure at rest and during exercise in chronic bronchitis - fact or fancy. Clinical Science, 37503.

Mills, I. H. (1968). The mechanisms of sodium retention in cor pulmonale - the role of potassium. In
Proceedings of the Association of Physicians of Gt. Britain and Ireland. Quarterly fournal of Medicine, 37, 654 .

Mitchell, R. S., Walker, S. H., and Maisel, J. C. (1968). The causes of death in chronic airway obstruction. II Myocardial infarction. American Review of Respiratory Diseases, 98, $6 \mathrm{II}$.

Moret, P. R., Bopp, P., and Panos, J. (1967). Coronary circulation and myocardial metabolism in chronic cor pulmonale. In Fifth World Congress of Cardiology Symposia, p. 158. Acta Cardiologica, Brussels.

Oakley, C. M., and Goodwin. J. F. (1967). Current clinical aspects of cor pulmonale. American fournal of Cardiology, 20, 842.

Platts, M. M., Hammond, J. D. S., and Stuart-Harris, C. H. (1960). A study of cor pulmonale in patients with chronic bronchitis. Quarterly fournal of Medicine, 29, 559.

Rees, H. A., Thomas, A. J., and Rossiter, C. (1964). The recognition of coronary heart disease in the presence of pulmonary disease. British Heart fournal, 26, 233.

Sadoul, P., Schrijen, F., Uffholtz, H., and Pham, Q. T. (1968). Evolution clinique de 195 pulmonaires chroniques soumis à un catheterisme du coeur droit entre 1957-1965. Bulletin de Physio-Pathologie Respiratoire, 4, 224.

Saunders, W. L. (1970). Heart disease and pneumoconiosis. Thorax, 25, 223

Schloerb, P. R., King, C. R., Kerby, G., and Ruth, W. E. (1970). Potassium depletion in patients with chronic respiratory failure. American Review of Respiratory Diseases, 102, 53.

Segel, N., and Bishop, J. M. (1966). The circulation in patients with chronic bronchitis and emphysema at rest and during exercise with special reference to the influence of changes in blood viscosity and blood volume on the pulmonary circulation. fournal of Clinical Investigation, 45, 1555.

Thomas, A. J., and Valabhji, P. (1969). Arrhythmias and tachycardia in pulmonary heart disease. British Heart fournal, 31, $49 \mathrm{I}$.

Turino, G. M., Goldring, R. M., and Fishman, A. P. (1965). Cor pulmonale in musculo-skeletal abnormalities of the thorax. Bulletin of the New York Academy of Medicine, 41, 959.

Wade, O. L., and Bishop, J. M. (1962). Cardiac Output and Regional Blood Flow, p. 150. Blackwell Scientific Publications, Oxford.

West, J. B. (1965). Ventilation/Blood Flow and Gas Exchange. Blackwell Scientific Publications, Oxford.

White, R. J., and Woodings, D. F. (I97I). Impaired water handling in chronic obstructive airways disease. British Medical fournal, 2, 56r.

Williams, J. F., Childress, R. H., Boyd, D. L., Higgs, L. M., and Behnke, R. H. (I968). Left ventricular function in patients with chronic obstructive pulmonary disease. fournal of Clinical Investigation, 47 , I 143.

World Health Organization (1963). Expert committee on chronic cor pulmonale. (World Health Organization. Technical Report Series, No. 213.) Circulation, 27, 594 .

Requests for reprints to Dr. Arthur J. Thomas, Llandough Hospital, Penarth, Glamorgan. 